\title{
SENSITIVITAS DAN SPESIFISITAS LINGKAR PINGGANG DALAM MENGIDENTIFIKASI KELEBIHAN BERAT BADAN DAN OBESITAS PADA WANITA DEWASA
}

\author{
Aulia Miladitiya \\ Magister Ilmu Gizi Universitas Diponegoro Semarang
}

\begin{abstract}
Obesity, Overweight, Sensitivity, Specificity, Waist Circumference. Body mass index couldn't differentiated correlation between body weight with muscle or body fat and indication distribution of body fat. Waist circumference measurement needed because it is convenient and strongly correlated with intra-abdominal fat content. This study aims to assess sensitivity and specificity of waist circumference measurement in identified overweight and obesity on adult women compared with body mass index as gold standard. This Study design is observational with cross sectional approach. Total of 80 women subjects aged >18-49 years old was selected using cluster random sampling. Sensitivity and specificity were analyzed from Receiver Operator Characteristic Curve. Cut-off waist circumference which used to identify overweight and obesity on adult women were $>80 \mathrm{~cm}$ and $>88 \mathrm{~cm}$. The use of $80,1 \mathrm{~cm}$ of waist circumference was shown to have a good sensitivity and specificity (82\% and $72 \%)$. Waist circumference have fair diagnostic power (area under curve was 0,784). Waist circumference can used to identify overweight and obesity because have sensitivity and specificity value good.
\end{abstract}

Keywords : Obesity, Overweight, Sensitivity, Specificity, Waist Circumference

Abstrak : Kelebihan Berat Badan, Lingkar Pinggang, Obesitas, Sensitivitas, Spesifisitas. Indeks massa tubuh tidak dapat membedakan antara hubungan berat badan dengan otot atau lemak tubuh dan indikasi distribusi lemak tubuh. Diperlukan indikator lingkar pinggang yang sederhana dan berhubungan kuat dengan lemak intra-abdomen. Tujuan penelitian ini untuk mengetahui sensitivitas dan spesifisitas lingkar pinggang dalam mengidentifikasi kelebihan berat badan dan obesitas pada wanita usia subur dibandingkan dengan IMT sebagai gold standar. Penelitian ini merupakan penelitian observasional dengan pendekatan cross sectional. Sebanyak 80 subyek wanita usia subur (>18-49 tahun) di Kabupaten Malang dipilih secara cluster random sampling. Uji sensitivitas dan spesifisitas menggunakan Receiver Operator Characteristic Curve. Cutoff lingkar pinggang yang digunakan untuk mengidentifikasi kelebihan berat badan dan obesitas adalah $>80 \mathrm{~cm}$ dan $>88 \mathrm{~cm}$. Kekuatan diagnostik pengukuran lingkar pinggang ditentukan berdasarkan area under curve. Berdasarkan analisis Receiver Operator Characteristic Curve, cut-off lingkar pinggang yang paling optimal dalam mengidentifikasi kegemukan adalah pada titik $80,1 \mathrm{~cm}$ dengan nilai sensitivitas $82 \%$ dan spesifisitas $72 \%$. Kekuatan diagnostik dari pengukuran lingkar pinggang dalam mengidentifikasi kelebihan berat badan dan obesitas pada WUS adalah sedang, berdasarkan nilai area under curve sebesar 0,784. Lingkar pinggang dapat digunakan untuk mengidentifikasi kelebihan berat badan dan obesitas karena mempunyai nilai 
sensitivitas dan spesifisitas yang baik.

Kata Kunci : Kelebihan Berat Badan, Lingkar Pinggang, Obesitas, Sensitivitas, Spesifisitas

\section{PENDAHULUAN}

Prevalensi obesitas wanita dewasa (>18 tahun) di Indonesia pada tahun sebesar $32,9 \%$, mengalami kenaikan sebesar $17,5 \%$ dari tahun $2010(15,5 \%)$ dan naik 18,1\% dari tahun $2007(13,9 \%)$. Jawa timur merupakan salah satu provinsi dengan prevalensi obesitas di atas nasional (Riskesdas, 2013). Obesitas sentral berhubungan dengan faktor risiko kardiovaskuler, hipertensi, diabetes, dislipidemia dan sindrom metabolik (Wen-Ya et al, 2013).

Pengukuran indeks massa tubuh (IMT) sangat berguna utuk mengidentifikasi kelebihan berat badan dan obesitas pada usia dewasa. IMT mempunyai keterbatasan yaitu tidak dapat membedakan antara hubungan berat badan dengan otot atau lemak tubuh dan tidak dapat memberikan indikasi distribusi lemak tubuh. Untuk melengkapi keterbatasan ini, diperlukan indikator lingkar pinggang (Fahmida dan Dillon, 2007).

Pengukuran lingkar pinggang sederhana dan berhubungan kuat dengan lemak intra-abdomen dan faktor risiko kardiovaskuler (Wen-Ya et al, 2013). Kriteria lingkar pinggang untuk wanita jika $>80 \mathrm{~cm}$ mengalami peningkatan risiko komplikasi metabolik dan $>88 \mathrm{~cm}$ berisiko sangat tinggi terhadap komplikasi metabolik (WHO, 2008).

Sensitivitas didefinisikan sebagai kemampuan suatu metode diagnostik untuk mendeteksi suatu penyakit. Spesifisitas didefinisikan sebagai kemampuan suatu metode diagnostik untuk menentukan bahwa subyek tidak sakit (Sastroasmoro, 2014). Perlu dilakukan pengujian sensitivitas dan spesifistas untuk mengetahui seberapa besar indikator lingkar pinggang mampu mengidentifikasi yang benar-benar gemuk dan tidak gemuk pada wanita usia subur dengan membandingkan dengan IMT sebagai gold standar.

\section{METODE PENELITIAN}

\begin{tabular}{rrr}
\multicolumn{2}{c}{ Penelitian ini merupakan } \\
penelitian observasional dengan
\end{tabular} pendekatan cross sectional. Sumber data yang digunakan adalah data sekunder yaitu data pre-dietetic internship tahun 2016 mahasiswa gizi Universitas Brawijaya Malang. Populasi target dari penelitian ini adalah wanita usia subur (>18-49 tahun) yang tinggal di Kabupaten Malang, sedangkan populasi terjangkau adalah wanita usia subur (>18-49 tahun) yang tinggal di 16 wilayah puskemas di Kabupaten Malang. Sampel dari penelitian ini adalah wanita usia subur (>18-49 tahun) yang tinggal di 4 wilayah Puskesmas di Kabupaten Malang dengan kriteria (baik sudah menikah atau belum dan tidak sedang menyusui atau hamil). Pada data sekunder, setiap wilayah puskesmas terdapat 20 responden WUS, sehingga total subyek dalam penelitian ini adalah 80 subyek. Penelitian ini menggunakan cluster random sampling. Sehingga terpilih 4 puskesmas yaitu Puskesmas Tajinan, Pujon, Jabung, Ardimulyo di Kabupaten Malang. Variabel yang diamati meliputi berat badan dan tinggi badan untuk menilai 
IMT, serta lingkar pinggang. Variabel tersebut diambil dari hasil data hasil pengolahan kuesioner pre-dietetic internship.

Teknik analisis data menggunakan uji diagnostik, yaitu menguji sensitivitas dan spesifisitas lingkar pinggang untuk mengidentifikasi kelebihan berat badan dan obesitas yang dibandingkan dengan IMT sebagai gold standard menggunakan crosstabs; nilai prediksi negatif dan nilai prediksi positif; Likelihood Ratio LR (+) dan LR (-); kurva ROC. Hasil uji sensitivitas dan spesifisitas diinterpretasikan amat baik ( $\mathrm{Se}$ dan $\mathrm{Sp}>$ 90\%); baik $(70 \%>$ Se dan $\mathrm{Sp}<90 \%)$; Cukup baik $(60 \%>$ Se dan Sp < 70\%); Kurang baik (Se dan $\mathrm{Sp}<60 \%$ (Waspadji, 2003). Area under curve (AUC) pada kurva ROC untuk menentukan kekuatan diagnostik dari pengukuran lingkar pinggang dalam mengidentifikasi kelebihan berat badan dan obesitas atau risiko terkena penyakit tidak menular. Interpretasi nilai AUC adalah sangat lemah (>50-60\%); lemah (>60-70\%); sedang (>70-80\%); baik (>80-90\%); sangat baik (90-100\%) (Meilani, 2012).

Analisis statistik dilakukan dengan menggunakan SPSS (version 16).Uji Normalitas menggunakan Kolmogorovsmirnov ( $>50)$ (Dahlan, 2014). Analisis univariat untuk melihat gambaran prevalensi wanita yang mengalami kelebihan berat badan dan obesitas berdasarkan cut-off point IMT dan lingkar pinggang, serta nilai mean, standar deviasi untuk data yang berdistribusi normal, rerata geometrik untuk data yang berdistribusi normal melalui transformasi menggunakan Lg10.

\section{HASIL PENELITIAN}

Hasil pengukuran antropometri yang disajikan pada Tabel 1 menunjukkan bahwa rerata tinggi badan WUS (>18-49 tahun) di 4 wilayah puskesmas Kabupaten Malang adalah $1,51 \mathrm{~m}$, rerata lingkar pinggang adalah $86,22 \mathrm{~cm}$, rerata IMT adalah $25,87 \mathrm{~kg} / \mathrm{m}^{2}$, rerata berat badan adalah $58,76 \mathrm{~kg}$. Jika melihat rerata IMT responden maka dapat diinterpretasikan bahwa responden termasuk dalam kategori kelebihan berat badan. Rerata lingkar pinggang subyek adalah $86,22 \mathrm{~cm}(>80$ $\mathrm{cm})$ yang berarti terjadi peningkatan risiko terhadap komplikasi metabolik.

\section{Tabel 1}

Hasil Pengukuran Antropometri

\begin{tabular}{cc}
\hline Parameter & Mean \pm SD \\
\hline Lingkar Pinggang $(\mathrm{cm})$ & $86,22 \pm 1,13$ \\
TB $(\mathrm{m})$ & $1,51 \pm 5,08$ \\
BB $(\mathrm{kg})^{*}$ & $58,76(\mathrm{IK} 95 \%$ \\
& $56,61-61)$ \\
$\mathrm{IMT}\left(\mathrm{kg} / \mathrm{m}^{2}\right)^{*}$ & $25,87(\mathrm{IK} 95 \%$ \\
& $24,97-26,8)$ \\
\hline
\end{tabular}

Persentase WUS (>18-49 tahun) yang mengalami kelebihan berat badan dan obesitas atau peningkatan risiko terhadap penyakit berdasarkan IMT $(\geq 23$ $\mathrm{kg} / \mathrm{m}^{2}$ ) pada penelitian ini sebesar $77,5 \%$. Berdasarkan indikator lingkar pinggang, sekitar 70\% WUS (>18-49 tahun) pada penelitian ini mengalami peningkatan risiko komplikasi metabolik (lingkar pinggang $>80 \mathrm{~cm}$ ).

Uji Diagnostik dilakukan dengan menghitung sensitivitas, spesifisitas, nilai duga positif, nilai duga negatif, Likelihood Ratio/ LR (+) dan LR (-) berdasarkan kategori lingkar pinggang dan IMT. Kategori lingkar pinggang disajikan pada Tabel 2. 
Tabel 2

Kategori Lingkar Pinggang dan Kategori IMT

\begin{tabular}{ccccc}
\hline & & $\begin{array}{l}\text { IMT } \\
(+)\end{array}$ & $(-)$ & Total \\
\hline LiPi & $(+)$ & 51 & 5 & 56 \\
& $(-)$ & 11 & 13 & 24 \\
\hline Total & & 62 & 18 & 80 \\
\hline
\end{tabular}

Hasil uji diagnostik meliputi nilai sensitivitas, spesifisitas, nilai duga positif, nilai duga negatif, Likelihood Ratio/ LR (+) dan LR (-) disajikan pada Tabel 3.

Tabel 3

Hasil Uji Diagnostik Indikator Lingkar Pinggang

\begin{tabular}{|c|c|}
\hline Parameter & \\
\hline Sensitivitas & $82 \%$ \\
\hline Spesifisitas & $72 \%$ \\
\hline NDP & $91 \%$ \\
\hline NDN & $54 \%$ \\
\hline LR $(+)$ & 2,93 \\
\hline LR (-) & 0,25 \\
\hline
\end{tabular}

sensitivitas dan spesifisitas indikator lingkar pinggang termasuk dalam kategori baik ( $\mathrm{Se}=82 ; \mathrm{Sp}=72 \%$ ). Nilai duga positif menunjukkan probabilitas seseorang benar-benar gemuk adalah sebesar 91\% jika hasil pengukuran menggunakan lingkar pinggang dinyatakan gemuk. Nilai duga negatif menunjukkan probabilitas seseorang benar-benar tidak gemuk adalah sebesar 54\% jika hasil pengukuran lingkar pinggang dinyatakan tidak gemuk. Nilai LR (+) indikator lingkar pinggang adalah sebesar 2,93, hal ini berarti subyek WUS yang gemuk memiliki kemungkinan 2,93 kali lebih tinggi terdeteksi gemuk oleh lingkar pinggang dibandingkan dengan subyek yang tidak gemuk. Nilai LR (-) sebesar 0,25 , hal ini berarti subyek WUS yang gemuk memiliki kemungkinan 0,25 kali lebih rendah terdeteksi tidak gemuk oleh lingkar pinggang dibandingkan dengan subyek yang tidak gemuk.

Gambar 1 menunjukkan bahwa kekuatan diagnostik dari pengukuran lingkar pinggang dalam mengidentifikasi kelebihan berat badan dan obesitas pada WUS adalah sedang, berdasarkan nilai AUC sebesar (0,784 atau 78,4\%).

ROC Curve

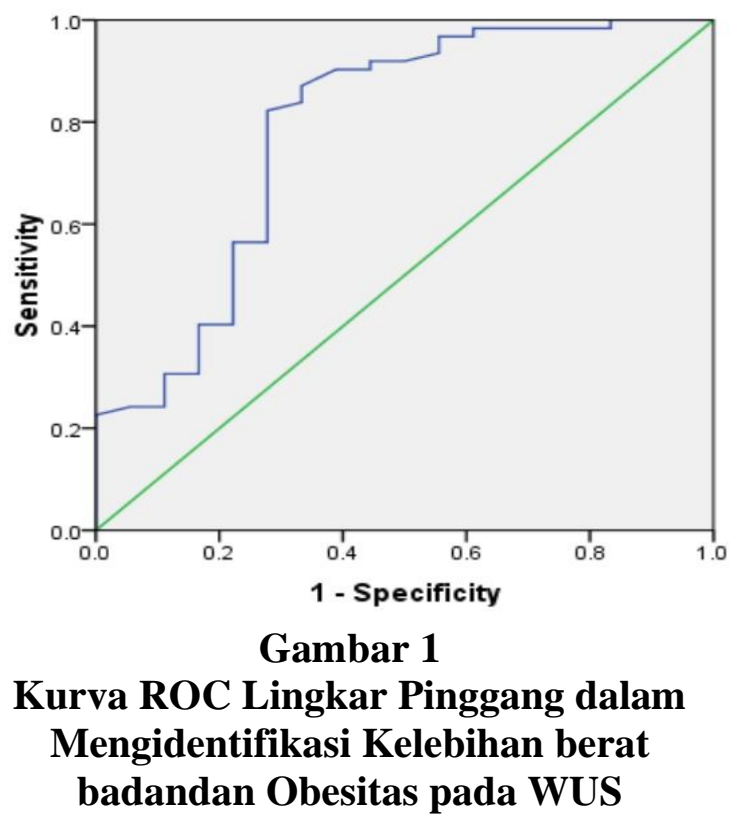

Selain mendapatkan nilai AUC, dari analisis kurva ROC juga dapat digunakan untuk menentukan cut-off optimal untuk ukuran lingkar pinggang dalam mengidentifikasi kelebihan berat badan dan obesitas pada WUS (>18-49 tahun) berdasarkan nilai sensitivitas dan spesifisitas yang paling baik. Pada penelitian ini diperoleh hasil bahwa ambang batas lingkar pinggang yang paling optimal dalam mengidentifikasi kegemukan adalah pada titik 80,1 cm karena memiliki nilai sensitivitas dan spesifisitas yang baik yaitu nilai sensitivitas $=82 \%$ dan spesifisitas $=72 \%$. 


\section{PEMBAHASAN}

IMT dapat dijadikan sebagai gold standar untuk mengidentifikasi kelebihan berat badan dan obesitas. Karena berdasarkan uji korelasi antara IMT dan lingkar pinggang mempunyai nilai korelasi positif yang signifikan baik pada subyek laki-laki maupun wanita. IMT digunakan sebagai parameter keseluruhan adiposit tubuh sedangkan lingkar pinggang digunakan sebagai indikator untuk adiposit abdominal (Odenigbo et al, 2011).

Hasil dari penelitian ini menunjukkan bahwa lingkar pinggang dapat menjadi indikator yang baik untuk mengidentifikasi kegemukan (lingkar pinggang $>80 \mathrm{~cm}$ ) dan tidak gemuk pada WUS (>18-49 tahun) karena mempunyai nilai sensitivitas dan spesifisitas yang baik $(\mathrm{Se}=82 \% ; \mathrm{Sp}=72 \%)$. Hasil penelitian ini hampir sama dalam kategori nilai sensitivitas tetapi tidak sama dalam kategori nilai spesifisitas lingkar pinggang dengan penelitian di Nigeria yang dilakukan pada subyek wanita berusia 2958 tahun, menyatakan bahwa lingkar pinggang merupakan indikator yang baik untuk mengidentifikasi obesitas (lingkar pinggang >88 $\mathrm{cm}$ ) dan untuk mengidentifikasi yang tidak obesitas tergolong cukup baik dengan IMT sebagai gold standar, sehingga lingkar pinggang dapat digunakan sebagai indikator penting dari obesitas global khususnya wanita $(\mathrm{Se}=100 \% ; \mathrm{Sp}=66,1 \%)$ (Odenigbo et al, 2011).

Berdasarkan analisis dari Kurva ROC diperoleh nilai AUC sebesar 0,784 yang berarti bahwa kekuatan diagnostik pengukuran lingkar pinggang untuk mengidentifikasi kegemukan (lingkar pinggang $>80 \mathrm{~cm}$ ) pada wanita usia subur usia $>18-49$ tahun adalah sedang. Hal ini sesuai dengan hasil penelitian serupa di India yang menyatakan bahwa pada cutoff lingkar pinggang $80 \mathrm{~cm}$ untuk wanita mempunyai nilai AUC 0,744 yang berarti mempunyai kekuatan diagnostik yang biasa/sedang (Karmakar et al, 2017). Selain nilai AUC, analisis kurva ROC juga dapat digunakan untuk menentukan cut-off point lingkar pinggang optimal, dari hasil penelitian ini cut-off point lingkar pinggang optimal yang direkomendasikan adalah $80,1 \mathrm{~cm}$, sama dengan cut-off point WHO untuk wanita yaitu $>80 \mathrm{~cm}$ termasuk dalam kategori peningkatan risiko terhadap sindrom metabolik (WHO, 2008). Cut-off point $80,1 \mathrm{~cm}$ mempunyai sensitivitas dan spesifisitas yang tergolong baik untuk mengidentifikasi kelebihan berat badan dan obesitas /peningkatan risiko terhadap komplikasi metabolik $(\mathrm{Se}=82 \%$; $\mathrm{Sp}=72 \%$ ). Hal ini didukung dengan hasil penelitian serupa di Jepang, yang menyatakan bahwa berdasarkan analisis kurva ROC, cut-off lingkar pinggang yang menghasilkan sensitivitas dan spesifisitas maksimal untuk memprediksi sindrom metabolik adalah $80 \mathrm{~cm}$ pada wanita $(\mathrm{Se}=75 \% ; \mathrm{Sp}=69 \%)$ (Takahashi,2009). Lingkar pinggang $>80$ $\mathrm{cm}$ setara dengan IMT 23,00-27,49 (overweight) yang berarti terdapat peningkatan risiko terkena penyakit tidak menular, sedangkan lingkar pinggang $>88$ $\mathrm{cm}$ setara dengan IMT $\geq 27,50$ (risiko sangat tinggi) (WHO, 2004).

Berdasarkan analisis nilai duga positif dan nilai duga negatif, pada penelitian ini diperoleh hasil bahwa nilai duga positif lingkar pinggang untuk mengidentifikasi kelebihan berat badan dan obesitas adalah sebesar 91\% yang berarti bahwa probabilitas seseorang benar-benar gemuk sebesar $91 \%$ jika dari 
hasil pengukuran dinyatakan gemuk. Nilai duga negatif menunjukkan probabilitas seseorang benar-benar tidak gemuk adalah sebesar 54\% jika dari hasil pengukuran dinyatakan tidak gemuk (Sastroasmoro, 2014). Nilai duga positif dan nilai duga negatif tergantung dari prevalensi dari subyek yang gemuk dari sampel populasi (Khon et al, 2013).

Berdasarkan analisis nilai LR (+) indikator lingkar pinggang adalah sebesar 2,93, berarti subyek WUS yang gemuk memiliki kemungkinan 2,93 kali lebih tinggi terdeteksi gemuk jika diukur menggunakan lingkar pinggang dibandingkan dengan subyek yang tidak gemuk. Nilai LR (-) sebesar 0,25 , berarti subyek WUS yang gemuk memiliki kemungkinan 0,25 kali lebih rendah terdeteksi tidak gemuk) jika diukur menggunakan lingkar pinggang dibandingkan dengan subyek yang tidak gemuk (Oktaviana dan Wimbarti, 2014).

\section{KESIMPULAN DAN SARAN}

Lingkar pinggang dapat digunakan untuk mengidentifikasi kelebihan berat badan dan obesitas karena mempunyai nilai sensitivitas $(82 \%)$ dan spesifisitas (72\%) yang baik. Kekuatan diagnostik pengukuran lingkar pinggang untuk mengidentifikasi kelebihan berat badan dan obesitas pada WUS termasuk kategori sedang, berdasarkan nilai AUC sebesar 0,784. Hasil dari penelitian ini merekomendasikan penggunaan cut-off lingkar pinggang untuk klasifikasi gemuk pada WUS yang optimal sama dengan cutoff lingkar pinggang untuk wanita berdasarkan WHO karena memiliki sensitivitas dan spesifisitas yang baik.

\section{DAFTAR RUJUKAN}

Dahlan, S. (2014). Statistik untuk Kedokteran dan Kesehatan: Deskriptif, Bivariat, dan Multivariat. Edisi 6.Jakarta : Epidemiologi Indonesia.

Fahmida, U., Dillon, DHS. (2007). Handbook Nutritional Assesssment.Jakarta : SEAMEOTROPMED RCCN UI.

Karmakar, A., Garg,S., Dasgupta, A., Paul, B., Maharana, SW. (2017). Sensitivity and Specificity of Waist Circumference as Single Screening Tool for Assessment of Kelebihan berat badanand Obesity.Int J Community Med Public Health.4(11):4254-4258.

Khon, MA., Carpenter, CR., Newman, TB. (2013).Understanding the Direction of Bias in Studies of Diagnostic Test Accuracy. ACADEMIC EMERGENCY MEDICINE; 20:1194-1206.

Meilani, M. (2012).Pendekatan Indeks Antropometri sebagai Alat Skrinning Hipertensi pada Orang Dewasa di Daerah Urban (Analisis Riskesdas 2007).Depok: Fakultas Kesehatan Masyarakat Universitas Indonesia.

Odenigbo UM., Odenigbo, UC., Oguejiofor, OC., Adogu, POU. (2011). Relationship of Waist Circumference, Waist Hip Ratio and Body Mass Index as Predictors of Obesity in Adult Nigerians.Pakistan Journal of Nutrition. 10(1): 15-18.

Oktaviana, M., Wimbarti S. (2014). Validasi klinik Strengths and Diffulties Quistionnaire (SDQ) sebagai Instrumen Skrinning Gangguan Tingkah Laku. 
JURNAL PSIKOLOGI VOLUME 41, NO. 1 : $101-114$.

Sastroasmoro, S., Ismael S. 2014. Dasar-

Dasar Metodologi Penelitian Klinis, Edisi ke-5. Jakarta: Sagung Seto.

Takahashi, M., Shimomura, K., Proks, P., Craig, TJ., Negishi, M., Akuzawa, M., et al. (2009). A Proposal of Combined Evaluation of Waist Circumference and BMI for the Diagnosis of Metabolic Syndrome.Endocrine Journal, 56 (9), 1079-1082.

Waspadji, S. (2003).Pengkajian Status Gizi. Studi Epidemiologi. Jakarta : FKUI.

Wen-Ya, MA., Chung-Yi, Y.,ShyangRong, S., et al. (2013). Measurement of Waist Circumference, Midabdominal or Iliac Crest?.Diabetes Care 36:1660-1666.

WHO Expert Consultation.(2004). Appropriate body-mass index for Asian populations and its implications for policy and intervention strategies. Lancet; 363: 157-63.

WHO Expert Consultation.(2008). Waist Circumference and Waist-to-Hip Ratio. Geneva: WHO. http://who.int. (diperoleh10 Desember 2017) 